\title{
A Nonlinear Analysis of the Real Exchange Rate-Consumption Relationship
}

\author{
Efthymios G. Pavlidis, Ivan Paya, and David A. Peel \\ Department of Economics, Lancaster University Management School,UK
}

\begin{abstract}
A variety of international macroeconomic models predict a relationship between the real exchange rate and relative consumption. The empirical evidence in favor of such a relationship is limited, the so-called Backus and Smith puzzle. In this paper, we extend the framework to allow for nonlinear shortrun dynamics and volatility changes across exchange rate regimes. Our nonlinear analysis indicates that long-run relationships in line with standard international business cycle models do exist for many OECD countries. Further, Monte Carlo experiments illustrate that the estimated nonlinear models can generate the Backus and Smith and the exchange rate disconnect puzzles. In this paper, we also contribute to the nonlinear real exchange rate literature by establishing a theoretical relationship between volatility and persistence. We show that neglecting this relationship, as has been common in applied work, results in biased estimates of impulse responses. In line with the theoretical results, our empirical findings suggest that the increase in volatility in the post-Bretton Woods era is associated with relatively fast mean reversion of the real exchange rate towards its equilibrium value.
\end{abstract}

Keywords: Exponential Smooth Transition Regression Model, Volatility Shifts, Conditional Heteroskedasticity, Impulse Response Analysis

JEL Classification: F41, C22, C52

\section{Introduction}

Nonlinear econometric models have become prevalent in explaining real exchange rate movements over the past two decades. These models are theoretically well motivated (see, e.g., Dumas, 1992), and exhibit superior performance compared to their linear counterparts (Taylor et al., 2001). The first generation of nonlinear models adopted univariate specifications and homoskedastic error structures (Michael et al., 1997: Taylor and Kilian, 2003). Subsequent work broadened this analysis by incorporating real factors -as suggested by the theoretical models of Balassa (1964) and Samuelson (1964)- and allowing for volatility changes across exchange rate regimes (Lothian and Taylor, 2008; Paya and Peel, 2006).

In this paper, we extend the above literature in two directions. First, we employ a set of economic fundamentals suggested by International Real Business Cycle (IRBC) models that has not been examined before in a nonlinear context. Namely, consumption series. This exercise is particularly interesting not only because it can provide useful insights regarding real exchange rate modeling, but also because nonlinear

\footnotetext{
${ }^{*}$ We are grateful to participants of the 2nd International Workshop on Financial Markets and Nonlinear Dynamics for useful comments and suggestions. Documentation about the data used in this paper is available from the Lancaster University data archive at http://dx.doi.org/10.17635/lancaster/researchdata/84. Correspondence to: Ivan Paya, Department of Economics, Lancaster University Management School, LA1 4YX, UK. E-mail: i.paya@lancaster.ac.uk
} 
dynamics may help to explain the discouraging results found by previous IRBC studies. Second, we add a new perspective to the Purchasing Power Parity (PPP) puzzle of Rogoff (1996) regarding the extremely slow mean reversion of real exchange rates. We do so by drawing attention to a widely neglected relationship in the nonlinear real exchange rate literature, the relationship between volatility shifts and speed of adjustment.

With respect to the first direction, standard IRBC models link relative prices to the ratio of marginal utilities of consumption in the home and foreign country (Backus and Smith, 1993; Kollmann, 1995). Under unrestricted trading in complete asset markets and with time-separable and iso-elastic preferences, a depreciation of the real exchange rate is associated with an increase in consumption in the home country with respect to the foreign 1 Following Backus and Smith (1993) and Kollmann (1995), several studies showed that the observed historical statistics are inconsistent with this prediction, which gave rise to the so-called Backus and Smith puzzle or the consumption real exchange rate anomaly.

A number of authors have provided theoretical justifications for these discouraging results by introducing incomplete asset markets, limited enforcement of international financial contracts, sticky prices in local currency pricing, non-traded goods production sectors and distribution services, hand-to-mouth agents, and habit persistence (Benigno and Thoenissen, 2008; Chari et al., 2002; Head et al., 2004; Kollmann, 2012). Their findings demonstrate that the nature of the underlying relationship is ambiguous with the magnitude of the theoretical contemporaneous correlation taking a wide range of values (from large positive to negative) depending on model assumptions. Likewise, the empirical relationship between real exchange rates and consumption series remains anything from clear (Head et al., 2004).

Standard IRBC models predict a linear long-run relationship between real exchange rates and consumption. However, they make no prediction about the functional form of the adjustment process. A common feature of the empirical IRBC studies to date is the assumption of a linear functional form. In a companion paper (Pavlidis et al., 2015), we provide evidence that cast doubts on the validity of this assumption. By applying both linear and nonlinear Granger causality tests to real exchange rate and consumption series, we show that allowing for nonlinearities results in a substantial increase in the number of rejections of the null hypothesis of no-Granger causality. Motivated by this finding, we argue that the nature of the relationship between real exchange rates and consumption reported in previous studies may be misleading due to the linear framework adopted.

With regards to the specific type of nonlinear dynamics, recent econometric analyses of real exchange data with constant or time-varying equilibrium present substantial evidence in favor of a smooth transition adjustment mechanism (see, e.g., Lothian and Taylor, 2008; Michael et al., 1997). The underlying idea is that mean reversion manifests itself as the deviation from the equilibrium rate becomes large in absolute value. Small deviations are left uncorrected due to the actions of heterogeneous agents, uncertainty regarding the equilibrium rate, or because they are not large enough to cover the sunk costs of international arbitrage (e.g., Kilian and Taylor, 2001). This type of nonlinear dynamics provides an explanation to two empirical regularities generated by linear models. First, the fact that exchange rate movements appear disconnected to movements in fundamentals and, second, that exchange rates are more volatile than fundamentals - the socalled exchange rate disconnect and excess volatility puzzles. Moreover, it goes some way towards solving the PPP puzzle, since models that allow for smooth transition dynamics show that mean reversion is much faster for large shocks than that reported for their linear counterparts (see, e.g., Taylor et al., 2001).

In the present study, we re-examine the relationship between real exchange rates and real consumption for fourteen OECD countries. By allowing for smooth transition dynamics and by extending the sample period used by previous studies, we attempt to overcome the limitations of linear methods and obtain a better approximation of long-run relationships. Moreover, motivated by the findings of numerous studies that

\footnotetext{
${ }^{1}$ In a one-good world and no trade frictions, international risk sharing implies that home and foreign consumption levels are always equal and, therefore, the real exchange rate is constant. Two factors that break this link are non-traded goods (Backus and Smith, 1993) and trade costs (Dumas, 1992).
} 
indicate that changes in the exchange rate regime are associated with substantial changes in real exchange rate volatility (see, e.g., Lothian and Taylor, 2008; Mussa, 1986), we allow for a level shift in the volatility of the real exchange rate around the collapse of the Bretton Woods system. This change in volatility is of particular interest in our nonlinear framework.

Previous nonlinear real exchange rate studies typically assume that the speed of mean reversion depends only on the size of the deviation of the real rate from its equilibrium value, and neglect changes in volatility when conducting impulse response analysis. In this paper, we establish a relationship between real exchange rate volatility and real exchange rate persistence, and show that neglecting this relationship results in biased estimates of impulse responses. The intuition is simple: high volatility regimes, such as the recent float, are associated with (on average) large deviations from the equilibrium which (in expectation) are absorbed faster compared to small deviations due to the nonlinear nature of the process.

Our empirical results provide strong evidence in favor of smooth transition nonlinearity, conditional heteroskedasticity, and a volatility change in the relationship between real exchange rates and consumption for the majority of cases. The estimated models produce parsimonious fits and the Generalized Impulse Response Functions (GIRF) derived from them suggest a fast adjustment to shocks, with much shorter halflives than those obtained in linear systems. In line with the theoretical results, the well-documented increase in volatility in the post-Bretton Woods period is associated with relatively fast reversion of the economy towards its time-varying equilibrium.

Finally, we employ Monte Carlo simulation techniques to examine whether the estimated models can explain the Backus and Smith and exchange rate disconnect puzzles. Regarding the former, we demonstrate that the sample correlation between the real exchange rate and relative consumption may be misleading since it frequently takes small or even negative values even though there is a well defined structural relationship between the variables. For the exchange rate disconnect puzzle, we find that linear cointegration tests may exhibit extremely low power, frequently failing to reject the null of no cointegration when there is in fact a long-run relationship.

\section{International Real Business Cycle Models}

Several theoretical models establish a link between the real exchange rate and consumption series. Our primary objective is not to test a particular model but to investigate the more basic hypothesis that a generic relationship between these variables exists. Although we do not restrict the empirical analysis to a specific theoretical framework, in this section, we briefly outline a standard IRBC model to provide a reference point for the interpretation of the results.

IRBC models comprise an extension of the closed economy Real Business Cycle models to an international setting where transactions take place both in goods as well as in financial markets (e.g., King et al., 1988). In this setting, the models exhibit risk sharing across countries and a link emerges between the real exchange rate and a ratio of marginal utilities (see, e.g., Chari et al.,2002). To illustrate this most simply, we follow Kollmann (1995) and assume a world with $K$ countries indexed by $k=1, \ldots, K$, each represented by an infinitely lived agent. Furthermore, it is assumed that the goods consumed differ across countries, which implies a non-constant real exchange rate. Each country's preferences are given by

$$
U_{k}=E_{s}\left[\sum_{t=s}^{\infty} \beta_{k}^{t-s} u_{k, t}\left(C_{k, t}\right)\right], \quad k=1, \ldots, K,
$$

where, $E[\cdot]$ is the expectations operator, $\beta_{k} \in(0,1)$ is country $k$ 's subjective discount factor, $u_{k, t}(\cdot)$ is country $k$ 's instantaneous utility function in period $t$, and $C_{k, t}$ denotes consumption in country $k$. In equilibrium, 
the risk sharing condition for any country pair $(i, j)$ and for all periods and states is

$$
Q_{t}=S_{t} \frac{P_{j, t}}{P_{i, t}}=\Lambda_{i, j} \frac{\beta_{j}^{t} m_{j, t}}{\beta_{i}^{t} m_{i, t}},
$$

where $Q_{t}$ is the real exchange rate in period $t, S_{t}$ denotes the nominal exchange rate (measured as units of currency $i$ per unit of currency $j$ ), $P_{k, t}$ denotes consumer prices for country $k, \Lambda_{i, j}$ is a constant, and $m_{k, t}$ is the marginal utility of consumption for country $k=i, j$. The above relation should hold even if there are frictions in goods and labor markets, such as sticky prices and sticky wages, because their effect is already reflected in consumption choices. Taking logs and assuming that the utility function is iso-elastic with exponent $1-\eta_{k}$, where $\eta_{k}$ denotes the coefficient of relative risk aversion of country $k=i, j$, Equation (2) yields the model tested by Kollmann (1995)

$$
q_{t}=\lambda_{i, j}+\ln \left(\beta_{j} / \beta_{i}\right) t+\eta_{i} c_{i, t}-\eta_{j} c_{j, t},
$$

where $q_{t}, \lambda_{i, j}, c_{i, t}$ and $c_{j, t}$ denote the logarithms of $Q_{t}, \Lambda_{i, j}, C_{i, t}$ and $C_{j, t}$, respectively. Given that the coefficient of risk aversion takes positive values, growth in domestic (foreign) consumption should lower (increase) the value of domestic currency. Backus and Smith (1993) impose identical risk aversion coefficients, as well as, subjective discount factors across countries. Under these restrictions, a country undergoing a real depreciation should experience relative consumption growth, with a rate depending on the elasticity of intertemporal substitution in consumption. It follows that the real exchange rate is positively correlated to relative consumption. However, this prediction is model-dependent and there are several studies that demonstrate how changes in assumptions can yield small or even negative correlations.

\section{Nonlinear Adjustment and Volatility Shifts}

A widely employed nonlinear real exchange rate model is the Exponential Smooth Transition Autoregressive (ESTAR) of Granger and Teräsvirta (1993). 2) Michael et al. (1997), Taylor et al. (2001) and Taylor and Kilian (2003) among others show that univariate ESTAR models can parsimoniously fit a number of real exchange rates series sampled at different frequencies and spanning different periods. Most importantly, the implied speed of mean reversion of the estimated models is much faster for large shocks compared to that of linear models. On the basis of the theoretical contributions of Balassa (1964) and Samuelson (1964), Lothian and Taylor (2008) and Paya and Peel (2006) extend the analysis to allow for a time-varying equilibrium given by economic fundamentals. Their findings show a statistically significant long-run relationship between relative per capita real income or relative wealth and the real exchange rate. Moreover, the authors provide evidence that the incorporation of equilibrium determinants in real exchange rate models leads to further improvement (with respect to the univariate models) in terms of the speed of mean reversion.

In this paper, we follow the above literature and allow the equilibrium rate to depend on consumption series while deviations from the equilibrium rate follow an Exponential Smooth Transition Autoregression (ESTAR) process. A general ESTAR representation for the deviation of the real exchange rate process from the equilibrium rate $q_{t}-\mu_{t}$ is given by

$$
q_{t}-\mu_{t}=\sum_{p=1}^{\bar{p}} \phi_{p}\left(q_{t-p}-\mu_{t-p}\right) G\left(q_{t-\bar{d}} ; \gamma, \mu_{t-\bar{d}}\right)+\epsilon_{t},
$$

\footnotetext{
${ }^{2}$ The smooth adjustment process is suggested in the analysis of Dumas (1992). Furthermore, Teräsvirta (1994) argues that if an aggregated process is observed, regime changes may be smooth rather than discrete as long as heterogeneous agents do not act simultaneously even if they individually make dichotomous decisions, which favors the use of the ESTAR over Threshold Autoregressive models.
} 
where $q_{t}$ is the real exchange rate, $\mu_{t}=\lambda_{i, j}+\ln \left(\beta_{j} / \beta_{i}\right) t+n_{i} c_{i, t}-n_{j} c_{j, t}$ is the long-run IRBC equilibrium, which is a function of consumption series, $G\left(q_{t-\bar{d}} ; \gamma, \mu_{t-\bar{d}}\right)=$

$\exp \left(-\gamma\left(q_{t-\bar{d}}-\mu_{t-\bar{d}}\right)^{2}\right)$ is the transition function, $\gamma \in[0, \infty)$ is the smoothness parameter, which determines the transition speed towards the equilibrium, $\bar{d}$ is a positive integer, and $\epsilon_{t}$ is a gaussian error term 3 Equation (4) is a popular reformulation of the ESTAR model proposed by Granger and Teräsvirta (1993). The exponential transition function, $G(\cdot)$, is particularly applicable because it implies symmetric adjustment for positive and negative deviations from the equilibrium. Further, the speed of adjustment is increasing with the smoothness parameter $\gamma$ and the absolute value of the past deviation from the equilibrium. A particularly interesting case is when $\sum_{p=1}^{\bar{p}} \phi_{p}=1$. In this case, at the equilibrium $G(\cdot)=1$ and $q_{t}-\mu_{t}$ will behave as a unit root process, while for larger deviations $G(\cdot) \in(0,1)$ and $q_{t}-\mu_{t}$ will become mean reverting. Hence, although $q_{t}-\mu_{t}$ is a globally mean reverting nonlinear process, it may exhibit a high degree of persistence, which provides an explanation for the low power of stationarity tests applied after the collapse of the Bretton Woods system.

Regarding the ESTAR parameterization, Taylor and Kilian (2003) argue that it is more intuitive to allow the effect of deviations from the equilibrium on the nonlinear dynamics to be cumulative. To this end, we also consider the following ESTAR transition function: $G\left(q_{t-d} ; \gamma, \mu_{t-d}\right)=\exp \left(-\gamma\left(\sum_{d=1}^{\bar{d}}\left(q_{t-d}-\right.\right.\right.$ $\left.\left.\mu_{t-d}\right)\right)^{2}$ ). In this case, when $\bar{d}$ differs from unity and the smoothness parameter $\gamma$ is significant, cumulative deviations are a more informative indicator of whether the market is moving towards the equilibrium value rather than a single past deviation of the process.

Volatility Shifts. It is well known that in a nonlinear framework, contrary to a linear one, volatility changes alter the mean reverting properties of a time series process. However, this property has been widely neglected in the real exchange rate literature. In order to illustrate the consequences of neglecting volatility changes when measuring real exchange rate persistence, we employ the simplest ESTAR model with $p=1, \bar{d}=1$ and equilibrium rate $\mu_{t}=0$, for all $t$,

$$
q_{t}=q_{t-1} \exp \left(\gamma q_{t-1}^{2}\right)+\epsilon_{t}
$$

We measure persistence by investigating the effect of a shock on the future behaviour of the real exchange rate. In our nonlinear framework, this can be accomplished by using the Generalised Impulse Response Function (GIRF) introduced by Koop et al. (1996)

$$
\operatorname{GIRF}\left(h, \delta, \Omega_{t-1}\right)=E\left[q_{t+h} \mid \epsilon_{t}=\delta, \Omega_{t-1}\right]-E\left[q_{t+h} \mid \epsilon_{t}=0, \Omega_{t-1}\right],
$$

where $h$ denotes the horizon, $\delta$ is the shock size, which is deterministic, and $\Omega_{t-1}$ is the information set available at time $t-1$. The time series is initially located at the equilibrium, i.e., $E\left[q_{t+h} \mid \epsilon_{t}=0, \Omega_{t-1}\right]=0$ for all $h$. It is easy to see that, for $h=1, q_{t+1} \mid \epsilon_{t}=\delta, \Omega_{t-1} \sim N\left(\bar{q}_{t+1}, \sigma_{\epsilon}^{2}\right)$ with $\bar{q}_{t+1}=\delta \exp \left(-\gamma \delta^{2}\right)$, which implies that the rate of shock absorption, $1-\exp \left(-\gamma \delta^{2}\right)$, is an increasing function of $\gamma$ and the magnitude of the shock. For $h=2$, the GIRF is given by

$$
E\left[q_{t+2} \mid \epsilon_{t}=\delta, \Omega_{t-1}\right]=\int q_{t+1} \exp \left(-\gamma q_{t+1}^{2}\right) f\left(q_{t+1}\right) d q_{t+1}=\frac{\exp \left(\frac{-\gamma \bar{q}_{t+1}^{2}}{1+2 \gamma \sigma_{\epsilon}^{2}}\right) \bar{q}_{t+1}}{\left(1+2 \gamma \sigma_{\epsilon}^{2}\right)^{3 / 2}},
$$

where $f\left(q_{t+1}\right)$ denotes the normal density. This establishes that the GIRF is a function not only of the shock and the smoothness parameter but also the second moment of the error term $\sigma_{\epsilon}^{2}$. At the extreme case that $\sigma_{\epsilon}^{2}=0$, the impulse response is given by $\exp \left(-\gamma \bar{q}_{t+1}^{2}\right) \bar{q}_{t+1}$, which is identical to extrapolating the

\footnotetext{
${ }^{3}$ For the empirical exercise, we restrict the parameter space by setting $\gamma=\tilde{\gamma}^{2}$. By doing so, we rule out explosive processes and increase the speed of convergence of the optimization algorithm.
} 
skeleton of the ESTAR model -the "naive" approach to nonlinear impulse response analysis (see Granger and Teräsvirta, 1993). While at the other extreme, $\sigma_{\epsilon}^{2} \rightarrow \infty$, the impulse response tends to zero and the shock absorption rate to a hundred percent. Using standard calculus, it can be shown that the impulse response moves from $\exp \left(-\gamma \bar{q}_{t+1}^{2}\right) \bar{q}_{t+1}$ to zero monotonically as we increase $\sigma_{\epsilon}^{2}$ from zero to infinity. Relationships between variance and persistence also exist for $h>2$, however, as with most nonlinear models, analytic expressions are not available. Figure 1 depicts GIRFs for the simple ESTAR(1) model with $\gamma=0.05$ and error variance $\sigma_{\epsilon}^{2} \in\{0,0.1,0.5,1\}$ for a shock of size $\delta=1$ and $h=2, \ldots, 20$.

Figure 1

Clearly, the speed of mean reversion of ESTAR processes increases with the variance of the error term. Given the documented increase in the volatility of real exchange rates after the collapse of the Bretton Woods system, this implies that deviations from the equilibrium rate may have been reverting faster in the recent period than previously thought. In the following section, we empirically quantify for the first time the effect of volatility changes on the speed of mean reversion by employing a variance function for the error term that allows for a volatility shift around the inception of floating exchange rates and also GARCH dynamics

$$
\sigma_{\epsilon, t}^{2}=\omega+\omega^{\mathrm{BW}} d_{t}^{\mathrm{BW}}+\alpha \epsilon_{t-1}^{2}+\xi \sigma_{\epsilon, t-1}^{2}, \quad \epsilon_{t}=\psi_{t} \sigma_{\epsilon, t}, \quad \psi_{t} \sim N(0,1),
$$

where $\omega, \omega^{\mathrm{BW}}, \alpha$ and $\xi$ are parameters and $d^{\mathrm{BW}}$ is a Bretton Woods dummy variable.

\section{Data and Empirical Results}

We use quarterly data for private consumption, nominal exchange rates and consumer price indices obtained from the International Financial Statistics database for fourteen OECD countries: Austria, Australia, Canada, Denmark, Finland, France, Italy, Japan, Norway, Netherlands, Sweden, Switzerland, the United Kingdom, and the United States, which we set as the reference country. Due to data availability the sample period differs across country pairs. The longest period is from 1957Q4 to 2010Q4 for Canada, Japan, and the United Kingdom, while the shortest is from 1977Q1 to 1998Q4 for Netherlands. The sample period for each country is reported in Tables 2 and 3 .

Table 1 reports correlations between real exchange rates and relative consumption series, as well as between their first differences. Inspection of the table reveals that the consumption real exchange rate anomaly is present in our extended data set. The estimated correlation coefficients vary widely across countries with the range of values being larger for levels, $[-0.75,0.51]$, than first differences, $[-0.12,0.13]$. These findings are similar to the ones reported in the empirical literature (see, e.g., Backus and Smith, 1993).

\section{TABLE 1}

We now turn to the results for the econometric models described in Section 3 . The parameterization of the estimated models, the inclusion of a time trend, the autoregressive lag length and the delay parameter are specified on the basis of residual diagnostics and the statistical significance of the model 4

\section{TABLES 2 and 3}

The first two panels of Tables 2 and 3 show parameter estimates for the mean and variance functions, and the corresponding $p$-values. Focusing first on the mean equation, we observe that there is strong evidence in favor of nonlinear dynamics since all transition parameters are statistically significant at conventional

\footnotetext{
${ }^{4}$ The maximum delay parameter considered was eight. Note that Teräsvirta's (1994) procedure for selecting the delay parameter is not applicable here due to the multivariate framework and the possibility of I(1) variables. Further, an autoregressive lag length of two gave satisfactory results for all countries.
} 
significance levels. The functional form of the nonlinear dynamics, however, differs across countries. In particular, the parameterization that allows the effect of previous deviations from the equilibrium on the speed of mean reversion to be cumulative is chosen for three countries and the typical ESTAR parameterization for the remaining. Further, the delay parameter varies from three to eight quarters. Hence, there are cases where the economy responds to deviations from the equilibrium with a considerable time lag.

The results for the mean equation are, overall, supportive of the existence of a long-run relationship between the real exchange rate and consumption series. For most countries, this relationship is in line with the predictions of standard IRBC models. That is, the real value of the dollar rises with real consumption abroad and decreases with real consumption at home. To be specific, out of a total of 26 coefficients on consumption series 22 are correctly signed, and 19 (18) are correctly signed and statistically significant at the ten (five) percent significance level 5 These findings are very encouraging when compared to those of previous IRBC studies that find insignificant or even negative relative risk aversion coefficients, casting serious doubts on international risk sharing. However, it should be noted that our estimates are still relatively small (ranging from close to zero to 1.5) when compared to other fields of economics (see, e.g., Layard et al., 2008).

For the US, we observe that the preference parameter $\eta_{\text {US }}$ differs across country pairs. This variation may arise due to factors such as different sample sizes and sample periods. Ideally, we would like to estimate a system where the parameter corresponding to the reference country is restricted to be the same across equations. Unfortunately, estimation of such a system is non-trivial due to the various nonlinear mean specifications, the potentially conditional heteroskedastic error processes and the breaks in volatility. As an alternative, we assume a log utility function for the US in the standard IRBC model and restrict $\eta_{\text {US }}$ to unity 6 The results for the restricted models (presented in Tables 5 and 6 in the Appendix) are, if anything, slightly more supportive of the theoretical IRBC predictions 7 In particular, the relative risk aversion coefficients of Canada and Switzerland from correctly signed but statistically insignificant become correctly signed and statistically significant; and the coefficient of France from incorrectly signed and statistically insignificant becomes correctly signed and statistically significant. Another pleasant feature of the restricted models with respect to the unrestricted models is that the implied relative risk aversion coefficients are, in most cases, larger.

Tables 2 and 3 also report coefficient estimates for the trend variable together with the corresponding $p$-values. We observe that the estimated coefficients, $\ln \left(\beta_{j} / \beta_{\mathrm{US}}\right)$, are statitically significant for about half of the countries. However, the size of the estimates is extremely small, which means that differences between discount factors are not substantial in economic terms. Among all the country pairs, the US-Canada has the smallest (in absolute size) estimate, -0.002 . This estimate, which corresponds to a ratio $\beta_{\text {Canada }} / \beta_{\text {US }}$ of 0.998 , is in line with the economic and cultural proximity of the two countries.

The results for the variance function are also noteworthy. In accordance with previous studies, in more than half of the cases the regression residuals exhibit ARCH or GARCH dynamics. Regarding volatility shifts, we observe that the coefficient on the Bretton Woods dummy is statistically significant for the countries for which long time series are available. Not surprisingly, the coefficient is also negatively signed which indicates a volatility increase after the collapse of the Bretton Woods system.

The last panel of the table reports residual diagnostics and test statistics for two null hypotheses. The first hypothesis corresponds to the Backus and Smith assumption of equal relative risk aversion coefficients across countries $\left(H_{0}: \eta_{\mathrm{US}}=\eta_{j}\right)$. This hypothesis is rejected at the five percent significance level for all

\footnotetext{
${ }^{5}$ The data for the countries for which a coefficient on consumption is wrongly signed span relatively short time periods, which may have an adverse impact on the estimation of the long-run relationship.

${ }^{6}$ The empirical evidence reported by Chetty (2006) and Bombardini and Trebbi (2012), in the context of labor supply and attitudes to risk, respectively, suggests that log utility may be a good approximation to agents utility function.

${ }^{7}$ We have also experimented with higher levels of relative risk aversion. Not surprisingly, the econometric models are a poor fit when the relative risk aversion parameter takes large values, such as five.
} 
countries but two and, hence, is not supported by the data. It follows that the correlation between the real exchange rate and relative consumption is not a proper statistic for testing IRBC models. The second hypothesis is that deviations from the equilibrium follow a unit root process at the equilibrium $\left(H_{0}: \sum_{p=1}^{\bar{p}} \phi_{p}=1\right)$, which is a typical restriction imposed on nonlinear real exchange rate models. This hypothesis cannot be rejected for most (10 out of 13) countries at the five percent significance level. Finally, residual diagnostics are satisfactory for each case. The Ljung-Box statistic, $Q(4)$, and the Lagrange Multiplier statistic, $\mathrm{ARCH}(4)$, are greater than the five percent critical values suggesting that the fitted residuals do no exhibit serial correlation and $\mathrm{ARCH}$ effects up to lag four.

\subsection{The PPP Puzzle: Economic Fundamentals and Volatility Shifts}

The findings of the previous subsection support the existence of a long-run relationship between the real exchange rate and economic fundamentals. Deviations from this long-run equilibrium appear to be governed by a smooth transition adjustment mechanism. From an international macroeconomics perspective, we are particularly interested in measuring the speed at which the economy reverts to the time-varying equilibrium during the post-Bretton Woods period, and make comparisons with the PPP equilibrium benchmark.

We measure the speed of adjustment by conducting impulse response analysis. Table 4 displays halflives of shocks equal to 10,30 and 50 percent for the estimated IRBC and PPP models 8 The results illustrate that small shocks are being absorbed much slower than large shocks. The fact that mean reversion becomes more apparent as the size of the deviation from the equilibrium increases supports the nonlinear nature of the adjustment process. Moreover, in many cases, half-lives are below the lower limit of three years reported by previous studies that employ linear models. Regarding the role of economic fundamentals in the adjustment mechanism, we observe that allowing for a time-varying equilibrium generally increases (and in some cases substantially) the speed of reversion to the long-run equilibrium. The effect, however, varies considerably across shock sizes, being larger for small shocks, and countries.

\section{TABLE 4}

The above findings complement and extend the findings of the existing nonlinear real exchange rate literature. The overall conclusion that emerges is that both volatility shifts and economic fundamentals can play a crucial role in explaining the behavior of real exchange rates.

\subsection{Monte Carlo Experiments}

In this section, we employ Monte Carlo simulations to explore whether the estimated nonlinear models can explain the empirical regularities noted in the literature regarding the magnitude of the contemporaneous correlation coefficient (the Backus and Smith puzzle), and the fact that movements in the exchange rate seem disconnected from movements in economic fundamentals (the exchange rate disconnect puzzle). For each country, we calibrate "fake" real exchange rate series by using the estimated models reported in Tables 2 and 3 and the actual consumption series. The sample size is set equal to the actual sample size and the number of replication to 1,000 .

Figures 2 and 3 show histograms of estimated correlation coefficients between the "fake" real exchange rate series and relative consumption and between the first differences of the variables. We observe that the results exhibit a close resemblance to the correlations for the actual data reported in Table 1 . A substantial proportion of the estimated correlations are negative for both levels and first differences, and the dispersion

\footnotetext{
${ }^{8}$ PPP models have been estimated by imposing the restriction of zero coefficients on the consumption series. Half-lives for the estimated PPP models are not shown for Japan, Italy and Switzerland because either convergence of the optimization algorithm was not achieved or the transition parameter was insignificantly different from zero so that the model was found to be a unit-root model.
} 
of the estimated correlations is much smaller for first differences than for levels. Thus, the estimated models can generate the Backus and Smith puzzle.

\section{FIGURE2 \& FIGURE 3}

Regarding the exchange rate disconnect puzzle, we concentrate on the power of linear cointegration techniques to detect the existence of a long-run relationship between the "fake" real exchange rate and actual consumption in the home and foreign countries. For this exercise, we use Johansen's (1991) maximum eigenvalue test. The specification adopted allows for a linear trend in the cointegrating relation and includes four lags of the first differences of the system variables. The nominal significance level is set to five percent. According to the simulation results, the power of the test varies substantially with the data generating process under consideration, taking values from only 8 to almost 100 percent. For 9 out of the 13 data generating processes, the power of the test is below 30 percent. Hence, even if a long-run relationship between the real exchange rate and economic fundamentals exists, linear models with homoskedastic disturbances will frequently fail to detect it and will falsely indicate that real exchange rates and fundamentals are disconnected.

\section{Conclusion}

Many international macroeconomic models predict that the equilibrium real exchange rate is determined by consumption in the home and foreign countries. Previous studies, that adopt linear models with homoskedastic error structures, fail to provide evidence in favor of this prediction. In this paper, we extend the empirical analysis to allow for volatility shifts across exchange rate regimes, conditional heteroskedastic errors, and nonlinear short-run dynamics. By using data for fourteen OECD countries, we provide evidence in favor of a long-run relationship. Furthermore, we show through calibrations that the above factors coupled with differences in relative risk aversion coefficients across countries can account for the Backus and Smith and the exchange rate disconnect puzzles. Finally, we contribute to the nonlinear real exchange rate literature by establishing a theoretical link between volatility and persistence in smooth transition models. We show that neglecting this link, as has been common in the literature, when volatility changes occur results in biased estimates of impulse responses. In line with the theory, our empirical findings suggest that large shocks have relatively short half-lives during the post-Bretton Woods period.

\section{References}

Backus, D. K. and Smith, G. W. (1993), "Consumption and Real Exchange Rates in Dynamic Economies With Non-Traded Goods," Journal of International Economics, 35, 297-316.

Balassa, B. (1964), "The Purchasing Power Parity Doctrine: A Reappraisal,” Journal of Political Economy, $72,584-596$.

Benigno, G. and Thoenissen, C. (2008), "Consumption and real exchange rates with incomplete markets and non-traded goods," Journal of International Money and Finance, 27, 926-948.

Bombardini, M. and Trebbi, F. (2012), "Risk Aversion and Expected Utility Theory: An Experiment with Large and Small Stakes," Journal of the European Economic Association, 10, 1348-99.

Chari, V. V., Kehoe, P. J., and McGrattan, E. R. (2002), "Can Sticky Price Models Generate Volatile and Persistent Real Exchange Rates?” Review of Economic Studies, 69, 533-63.

Chetty, R. (2006), “A new method of estimating risk aversion,” American Economic Review, 96, 1821-1834. 
Dumas, B. (1992), "Dynamic Equilibrium and the Real Exchange Rate in Spatially Separated World," Review of Financial Studies, 5, 153-180.

Granger, C. W. J. and Teräsvirta, T. (1993), Modelling Nonlinear Economic Relationships, Oxford University Press.

Head, A. C., Mattina, T. D., and Smith, G. W. (2004), "Real Exchange Rates, Preferences, and Incomplete Markets: Evidence, 1961-2001," Canadian Journal of Economics, 37, 782-801.

Johansen, S. (1991), "Estimation and Hypothesis Testing of Cointegration Vectors in Gaussian Vector Autoregressive Models," Econometrica, 59, 1551-80.

Kilian, L. and Taylor, M. P. (2001), "Why Is It So Difficult to Beat the Random Walk Forecast of Exchange Rates,” Working Paper Series 088, European Central Bank.

King, R. G., Plosser, C. I., and Rebelo, S. T. (1988), "Production, Growth and Business Cycles, I. The Basic Neoclassical Model," Journal of Monetary Economcis, 21, 195-232.

Kollmann, R. (1995), "Consumption, Real Exchange Rates and the Structure of International Asset markets," Journal of International Money and Finance, 14, 191-211.

- (2012), "Limited Asset Market Participation and the Consumption-Real Exchange Rate Anomaly," Canadian Journal of Economics, 45, 566-584.

Koop, G., Pesaran, M. H., and Potter, S. M. (1996), "Impulse Response Analysis in Nonlinear Multivariate Models," Journal of Econometrics, 74, 119-147.

Layard, R., Mayraz, G., and Nickell, S. (2008), "The marginal utility of income," Journal of Public Economics, 92, 1846-1857.

Lothian, J. R. and Taylor, M. P. (2008), "Real Exchange Rates Over the Past Two Centuries: How Important is the Harrod-Balassa-Samuelson Effect?” Economic Journal, 118, 1742-1763.

Michael, P., Nobay, A. R., and Peel, D. A. (1997), "Transactions Costs and Nonlinear Adjustment in Real Exchange Rates: An Empirical Investigation,” Journal of Political Economy, 105, 862-879.

Mussa, M. L. (1986), "Nominal Exchange Rate Regimes and the Behaviour of Real Exchange Rates: Evidence and Implications," Carnegie-Rochester Conference Series on Public Policy, 25, 117-214.

Pavlidis, E. G., Paya, I., and Peel, D. A. (2015), "Testing for linear and nonlinear Granger causality in the real exchange rate-consumption relation," Economics Letters, 132, 13-17.

Paya, I. and Peel, D. A. (2006), "A New Analysis of the Determinants of the Real Dollar-Sterling Exchange Rate: 1871-1994," Journal of Money, Credit and Banking, 38, 1971-1990.

Rogoff, K. S. (1996), “The Purchasing Power Parity Puzzle,” Journal of Economic Literature, 34, 647-668.

Samuelson, P. (1964), "Theoretical Notes on Trade Problems," Review of Economics and Statistics, 46, $145-154$.

Taylor, M. P. and Kilian, L. (2003), "Why Is It So Difficult to Beat the Random Walk Forecast of Exchange Rates?” Journal of International Economics, 60, 85-107. 
Taylor, M. P., Peel, D. A., and Sarno, L. (2001), "Nonlinear Mean-Reversion in Real Exchange Rates: Toward a Solution to the Purchasing Power Parity Puzzles," International Economic Review, 42, 10151042.

Teräsvirta, T. (1994), "Specification, Estimation, and Evaluation of Smooth Transition Autoregressive Models," Journal of the American Statistical Association, 89, 208-218.

Table 1: The Backus and Smith Puzzle

\begin{tabular}{lcc}
\hline Country & $\operatorname{corr}(q, \tilde{c})$ & $\operatorname{corr}(\Delta q, \Delta \tilde{c})$ \\
\hline Austria & -0.673 & 0.128 \\
Australia & -0.239 & 0.049 \\
Canada & 0.168 & -0.013 \\
Denmark & 0.173 & -0.071 \\
Finland & 0.225 & -0.123 \\
France & 0.090 & -0.021 \\
Italy & -0.282 & 0.023 \\
Japan & -0.740 & 0.118 \\
Netherlands & -0.229 & -0.125 \\
Norway & -0.389 & 0.007 \\
Sweden & -0.347 & 0.031 \\
Switzerland & 0.482 & 0.046 \\
U.K. & 0.513 & 0.102 \\
\hline Range & {$[-0.740,0.513]$} & {$[-0.123,0.128]$}
\end{tabular}

Notes: The table reports correlations between the log real exchange rate, $q$, and log relative consumption, $\tilde{c}$, and between the first differences of the variables. 
Table 2: The Consumption-Real Exchange Rate Relationship

\begin{tabular}{|c|c|c|c|c|c|c|c|}
\hline Country $(j)$ & Australia & Austria & Canada & Denmark & Finland & France & Italy \\
\hline \multirow[t]{2}{*}{ Period } & 1959Q3/ & 1957Q1/ & 1957Q1/ & 1977Q1/ & 1970Q1/ & 1970Q1/ & 1970Q1/ \\
\hline & 2010Q4 & 1998Q4 & 2010Q4 & 2010Q4 & 1998Q4 & 1998Q4 & 1998Q4 \\
\hline \multicolumn{8}{|c|}{ Mean Equation } \\
\hline \multirow[t]{2}{*}{$\eta_{\mathrm{US}}$} & 0.161 & 0.826 & 0.316 & 0.975 & 1.050 & 1.236 & 0.835 \\
\hline & [0.027] & {$[0.000]$} & {$[0.000]$} & {$[0.026]$} & {$[0.001]$} & {$[0.000]$} & {$[0.000]$} \\
\hline \multirow[t]{2}{*}{$\eta_{j}$} & 0.189 & 0.175 & 0.080 & -0.085 & -0.831 & -0.006 & 0.309 \\
\hline & [0.006] & [0.032] & {$[0.470]$} & {$[0.793]$} & {$[0.003]$} & {$[0.985]$} & [0.036] \\
\hline \multirow[t]{2}{*}{$\gamma$} & 1.163 & 2.063 & 1.869 & 2.101 & 3.500 & 2.701 & 3.053 \\
\hline & {$[0.000]$} & {$[0.000]$} & {$[0.000]$} & {$[0.000]$} & {$[0.000]$} & {$[0.000]$} & {$[0.000]$} \\
\hline $\bar{d}$ & 6 & 8 & 4 & 8 & 8 & 8 & 5 \\
\hline \multirow{2}{*}{$\ln \left(\frac{\beta_{j}}{\beta_{\mathrm{US}}}\right)$} & & & -0.002 & -0.006 & -0.008 & -0.008 & \\
\hline & & & {$[0.012]$} & {$[0.052]$} & [0.002] & {$[0.004]$} & \\
\hline \multicolumn{8}{|c|}{ Variance Equation } \\
\hline \multirow[t]{2}{*}{$\omega$} & $1.32 \times 10^{-3}$ & $1.62 \times 10^{-4}$ & $2.52 \times 10^{-5}$ & & & & $2.95 \times 10^{-4}$ \\
\hline & {$[0.000]$} & {$[0.000]$} & {$[0.075]$} & & & & [0.182] \\
\hline \multirow[t]{2}{*}{$\alpha$} & 0.606 & 0.257 & 0.056 & & & & 0.308 \\
\hline & {$[0.000]$} & [0.009] & {$[0.021]$} & & & & [0.081] \\
\hline \multirow[t]{2}{*}{$\xi$} & & 0.707 & 0.904 & & & & 0.531 \\
\hline & & {$[0.000]$} & {$[0.000]$} & & & & {$[0.030]$} \\
\hline$w^{\mathrm{BW}}$ & $\begin{array}{c}-1.31 \times 10^{-3} \\
{[0.000]}\end{array}$ & $\begin{array}{c}-1.38 \times 10^{-4} \\
{[0.000]}\end{array}$ & $\begin{array}{c}-1.78 \times 10^{-5} \\
{[0.114]}\end{array}$ & & & & \\
\hline \multirow[t]{2}{*}{$F_{\mathrm{RA}}$} & 0.360 & 222.443 & 3.619 & 5.491 & 20.417 & 7.355 & 88.148 \\
\hline & [0.549] & {$[0.000]$} & [0.059] & {$[0.021]$} & {$[0.000]$} & {$[0.008]$} & {$[0.000]$} \\
\hline \multirow[t]{2}{*}{$F_{\mathrm{UR}}$} & 1.731 & 4.249 & 0.975 & 0.984 & 2.462 & 1.083 & 7.924 \\
\hline & [0.190] & [0.041] & {$[0.325]$} & [0.323] & [0.120] & [0.301] & [0.006] \\
\hline \multirow[t]{2}{*}{$Q(4)$} & 4.374 & 2.253 & 5.929 & 1.233 & 0.972 & 1.007 & 3.150 \\
\hline & {$[0.358]$} & [0.689] & [0.205] & [0.873] & [0.914] & [0.909] & [0.533] \\
\hline \multirow[t]{2}{*}{$\mathrm{ARCH}(4)$} & 0.306 & 0.211 & 0.377 & 0.758 & 0.386 & 2.006 & 0.522 \\
\hline & [0.874] & [0.932] & [0.825] & {$[0.555]$} & [0.818] & [0.100] & [0.720] \\
\hline
\end{tabular}

Notes: The table reports estimates of the econometric models in Equations (4) and (6). Figures in square brackets denote $p$-values. (C) indicates the ESTAR parameterization that allows the effect of past deviations from the equilibrium on the speed of mean reversion to be cumulative. The Wald statistic $F_{\mathrm{RA}}$ corresponds to the null hypothesis $H_{0}: \eta_{\mathrm{US}}=\eta_{j}$. $F_{\mathrm{UR}}$ corresponds to the null hypothesis that the process has a unit root at the equilibrium, $H_{0}: \sum_{p=1}^{2} \phi_{p}=1$. $Q(4)$ denotes the Ljung-Box $Q$-statistic for serial correlation up to four quarters and $\mathrm{ARCH}(4)$ is the $\mathrm{LM}$ test statistic for conditional heteroskedasticity up to four quarters. 
Table 3: The Consumption-Real Exchange Rate Relationship

\begin{tabular}{|c|c|c|c|c|c|c|}
\hline Country $(j)$ & Japan & Netherlands & Norway & Sweden & Switzerland & U.K. \\
\hline \multirow[t]{2}{*}{ Period } & 1957Q1/ & 1977Q1/ & 1961Q1/ & 1963Q1/ & 1970Q1/ & 1957Q1/ \\
\hline & 2010Q4 & 1998Q4 & 2010Q4 & 2010Q4 & 2010Q4 & 2010Q4 \\
\hline \multicolumn{7}{|c|}{ Mean Equation } \\
\hline \multirow[t]{2}{*}{$\eta_{\mathrm{us}}$} & 0.255 & 1.478 & 0.684 & 0.181 & 0.391 & 0.392 \\
\hline & [0.307] & [0.001] & {$[0.000]$} & [0.004] & {$[0.056]$} & {$[0.001]$} \\
\hline \multirow[t]{2}{*}{$\eta_{j}$} & 0.278 & -0.089 & 0.160 & 0.329 & 0.067 & 0.286 \\
\hline & {$[0.006]$} & {$[0.800]$} & {$[0.020]$} & {$[0.000]$} & [0.840] & {$[0.023]$} \\
\hline \multirow[t]{2}{*}{$\gamma$} & 0.627 & 3.175 & 0.633 & 1.136 & 0.166 & 0.271 \\
\hline & {$[0.000]$} & {$[0.000]$} & {$[0.000]$} & {$[0.000]$} & [0.001] & {$[0.000]$} \\
\hline $\bar{d}$ & 8 & 8 & $3(\mathrm{C})$ & 8 & $8(\mathrm{C})$ & $8(\mathrm{C})$ \\
\hline \multirow{2}{*}{$\ln \left(\frac{\beta_{j}}{\beta_{\mathrm{US}}}\right)$} & 0.006 & -0.011 & -0.003 & & & \\
\hline & {$[0.000]$} & {$[0.000]$} & [0.017] & & & \\
\hline \multicolumn{7}{|c|}{ Variance Equation } \\
\hline \multirow[t]{2}{*}{$\omega$} & $2.04 \times 10^{-3}$ & & $1.62 \times 10^{-3}$ & $1.45 \times 10^{-3}$ & & $1.42 \times 10^{-3}$ \\
\hline & {$[0.000]$} & & {$[0.000]$} & {$[0.000]$} & & {$[0.000]$} \\
\hline \multirow[t]{2}{*}{$\alpha$} & 0.248 & & 0.135 & 0.430 & & 0.386 \\
\hline & [0.012] & & [0.083] & [0.001] & & {$[0.000]$} \\
\hline \multicolumn{7}{|l|}{$\xi$} \\
\hline \multirow[t]{2}{*}{$w^{\mathrm{BW}}$} & $-1.94 \times 10^{-3}$ & & $-1.51 \times 10^{-3}$ & $-1.41 \times 10^{-3}$ & & $-1.25 \times 10^{-3}$ \\
\hline & {$[0.000]$} & & {$[0.000]$} & {$[0.000]$} & & {$[0.000]$} \\
\hline \multirow[t]{2}{*}{$F_{\mathrm{RA}}$} & 0.011 & 12.699 & 9.739 & 7.478 & 3.564 & 9.150 \\
\hline & [0.916] & [0.001] & [0.002] & [0.007] & [0.061] & [0.003] \\
\hline \multirow[t]{2}{*}{$F_{\mathrm{UR}}$} & 0.257 & 3.077 & 8.784 & 0.136 & 0.006 & 1.341 \\
\hline & [0.613] & [0.084] & [0.003] & [0.713] & [0.936] & {$[0.248]$} \\
\hline \multirow[t]{2}{*}{$Q(4)$} & 9.427 & 0.312 & 1.793 & 1.887 & 3.062 & 5.704 \\
\hline & [0.051] & [0.989] & [0.774] & [0.757] & {$[0.548]$} & [0.222] \\
\hline \multirow[t]{2}{*}{$\mathrm{ARCH}(4)$} & 0.629 & 0.782 & 0.105 & 0.117 & 1.374 & 0.726 \\
\hline & [0.643] & {$[0.540]$} & [0.981] & [0.976] & [0.246] & {$[0.575]$} \\
\hline
\end{tabular}

Notes: The table reports estimates of the econometric models in Equations (4) and (6). Figures in square brackets denote $p$-values. (C) indicates the ESTAR parameterization that allows the effect of past deviations from the equilibrium on the speed of mean reversion to be cumulative. The Wald statistic $F_{\mathrm{RA}}$ corresponds to the null hypothesis $H_{0}: \eta_{\mathrm{US}}=\eta_{j}$. $F_{\mathrm{UR}}$ corresponds to the null hypothesis that the process has a unit root at the equilibrium, $H_{0}: \sum_{p=1}^{2} \phi_{p}=1$. $Q(4)$ denotes the Ljung-Box $Q$-statistic for serial correlation up to four quarters and $\mathrm{ARCH}(4)$ is the $\mathrm{LM}$ test statistic for conditional heteroskedasticity up to four quarters. 
Table 4: Estimated Half-Lives for IRBC and PPP Models

\begin{tabular}{|c|c|c|c|c|c|c|}
\hline \multirow[b]{2}{*}{ Country/Shock (\%): } & \multicolumn{3}{|c|}{ PPP equilibrium } & \multicolumn{3}{|c|}{ IRBC equilibrium } \\
\hline & 10 & 30 & 50 & 10 & 30 & 50 \\
\hline Australia & 12 & 8 & 7 & 11 & 8 & 7 \\
\hline Austria & 18 & 14 & 12 & 12 & 9 & 8 \\
\hline Canada & 20 & 6 & 5 & 10 & 5 & 4 \\
\hline Denmark & 12 & 9 & 9 & 13 & 9 & 8 \\
\hline Finland & 12 & 9 & 9 & 12 & 9 & 8 \\
\hline France & 11 & 9 & 8 & 12 & 9 & 8 \\
\hline Italy & - & - & - & 8 & 6 & 5 \\
\hline Japan & - & - & - & 18 & 12 & 10 \\
\hline Netherlands & 13 & 9 & 8 & 13 & 9 & 8 \\
\hline Norway & $>60$ & $>60$ & 18 & 9 & 3 & 3 \\
\hline Sweden & 13 & 10 & 9 & 13 & 10 & 9 \\
\hline Switzerland & - & - & - & 8 & 6 & 5 \\
\hline U.K. & 9 & 5 & 4 & 8 & 5 & 3 \\
\hline
\end{tabular}

Notes: The table reports half-lives for the PPP and the International Real Business Cycle models. A - indicates that an estimate is not available because the transition parameter in the univariate ESTAR model was not found statistically significant. The maximum horizon considered in the impulse response analysis is 60 quarters. $>60$ indicates that the half-life exceeds the maximum horizon.

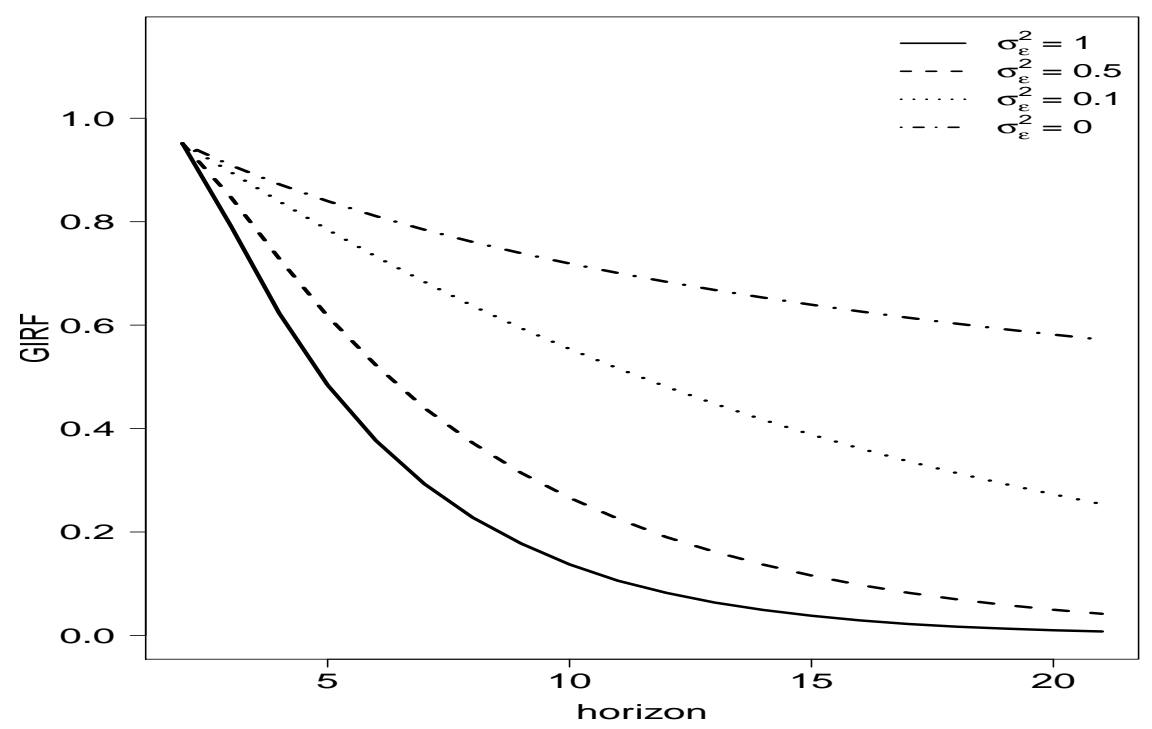

Figure 1: GIRFs for the simple ESTAR(1) model with error variance $\sigma_{\epsilon}^{2} \in\{0,0.1,0.5,1\}$. 

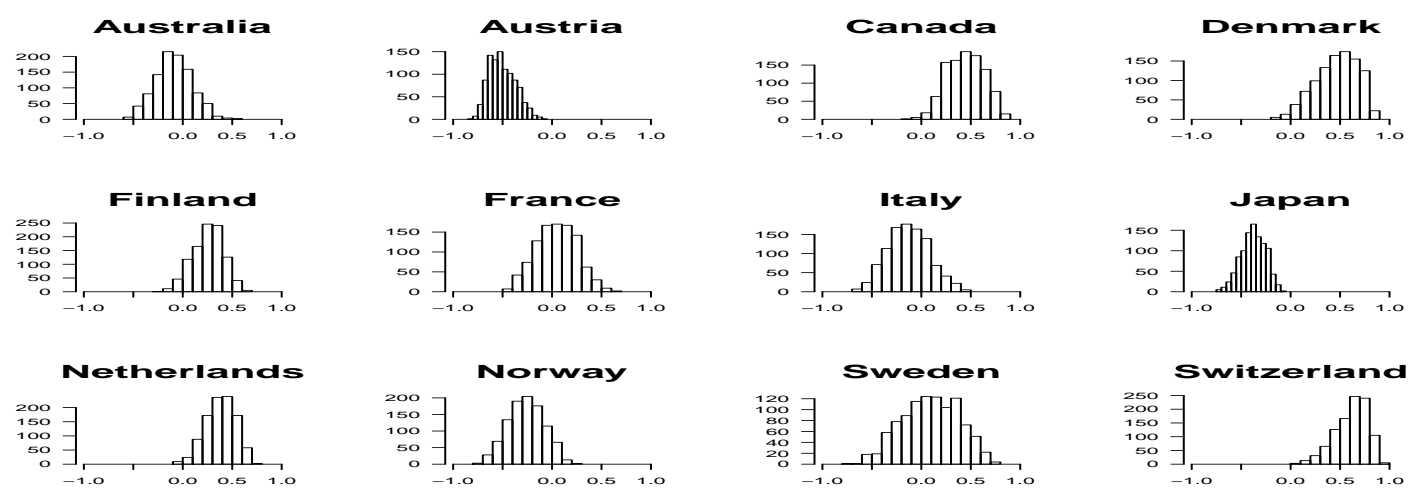

U. $\mathbf{c}$.

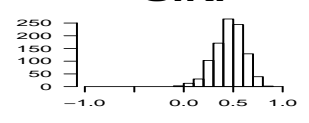

Figure 2: Histograms of simulated correlations between the log real exchange rate and log relative consumption.
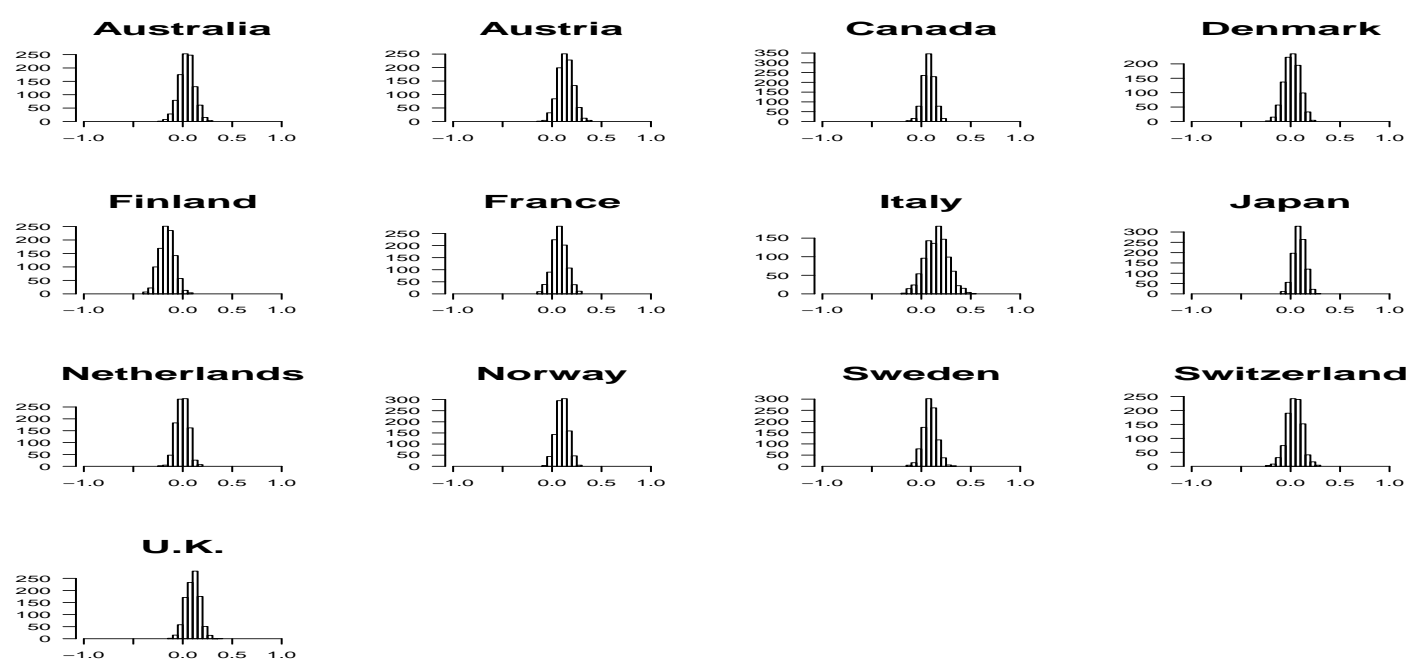

Figure 3: Histograms of simulated correlations between the first differences of the log real exchange rate and $\log$ relative consumption.

\section{Appendix}


Table 5: The Consumption-Real Exchange Rate Relationship (Log-Utility Restriction for the US)

\begin{tabular}{|c|c|c|c|c|c|c|c|}
\hline Country $(j)$ & Australia & Austria & Canada & Denmark & Finland & France & Italy \\
\hline \multirow[t]{2}{*}{ Period } & 1959Q3/ & 1957Q1/ & 1957Q1/ & 1977Q1/ & 1970Q1/ & 1970Q1/ & 1970Q1/ \\
\hline & 2010Q4 & 1998Q4 & 2010Q4 & 2010Q4 & 1998Q4 & 1998Q4 & 1998Q4 \\
\hline \multicolumn{8}{|c|}{ Mean Equation } \\
\hline \multirow[t]{2}{*}{$\eta_{j}$} & 0.495 & 0.292 & 0.280 & -0.077 & 0.017 & 0.816 & 0.437 \\
\hline & {$[0.000]$} & [0.000] & [0.004] & {$[0.800]$} & [0.957] & {$[0.004]$} & {$[0.000]$} \\
\hline \multirow[t]{2}{*}{$\gamma$} & 0.427 & 2.024 & 1.540 & 2.109 & 2.571 & 3.446 & 3.042 \\
\hline & [0.045] & {$[0.000]$} & {$[0.000]$} & {$[0.000]$} & [0.000] & {$[0.000]$} & {$[0.000]$} \\
\hline $\bar{d}$ & 6 & 8 & 4 & 8 & 8 & 8 & 5 \\
\hline \multirow{2}{*}{$\ln \left(\frac{\beta_{j}}{\beta_{\mathrm{US}}}\right)$} & & & -0.006 & -0.006 & -0.007 & -0.008 & \\
\hline & & & {$[0.000]$} & {$[0.000]$} & {$[0.001]$} & {$[0.000]$} & \\
\hline \multicolumn{8}{|c|}{ Variance Equation } \\
\hline \multirow[t]{2}{*}{$\omega$} & $1.58 \times 10^{-3}$ & $3.60 \times 10^{-4}$ & $1.17 \times 10^{-5}$ & & & & $3.03 \times 10^{-4}$ \\
\hline & {$[0.000]$} & [0.314] & {$[0.370]$} & & & & [0.182] \\
\hline \multirow[t]{2}{*}{$\alpha$} & 0.339 & 0.318 & 0.063 & & & & 0.299 \\
\hline & {$[0.002]$} & {$[0.022]$} & {$[0.047]$} & & & & {$[0.094]$} \\
\hline \multirow[t]{2}{*}{$\xi$} & & 0.572 & 0.928 & & & & 0.535 \\
\hline & & [0.004] & {$[0.000]$} & & & & [0.034] \\
\hline \multirow[t]{2}{*}{$w^{\mathrm{BW}}$} & $-1.53 \times 10^{-3}$ & $-3.15 \times 10^{-4}$ & $-9.96 \times 10^{-6}$ & & & & \\
\hline & {$[0.000]$} & {$[0.340]$} & {$[0.268]$} & & & & \\
\hline \multirow[t]{2}{*}{$F_{\mathrm{RA}}$} & 24.687 & 346.979 & 55.595 & 12.513 & 9.399 & 42.406 & 203.162 \\
\hline & [0.000] & {$[0.000]$} & [0.000] & {$[0.001]$} & [0.003] & {$[0.000]$} & {$[0.000]$} \\
\hline \multirow[t]{2}{*}{$F_{\mathrm{UR}}$} & 0.026 & 4.589 & 2.018 & 1.051 & 0.875 & 2.331 & 8.246 \\
\hline & [0.871] & [0.034] & [0.157] & [0.307] & [0.352] & {$[0.130]$} & [0.005] \\
\hline \multirow[t]{2}{*}{$Q(4)$} & 5.229 & 2.081 & 8.139 & 1.237 & 1.045 & 0.949 & 3.567 \\
\hline & [0.265] & [0.721] & [0.087] & {$[0.872]$} & [0.903] & [0.918] & [0.468] \\
\hline \multirow[t]{2}{*}{$\mathrm{ARCH}(4)$} & 0.642 & 0.295 & 0.660 & 0.757 & 1.854 & 0.421 & 0.533 \\
\hline & [0.633] & [0.881] & [0.620] & {$[0.555]$} & [0.125] & [0.793] & [0.712] \\
\hline
\end{tabular}

Notes: The table reports estimates of the econometric models in Equations (4) and (6). Figures in square brackets denote $p$-values. (C) indicates the ESTAR parameterization that allows the effect of past deviations from the equilibrium on the speed of mean reversion to be cumulative. The Wald statistic $F_{\mathrm{RA}}$ corresponds to the null hypothesis $H_{0}: \eta_{j}=1 . F_{\mathrm{UR}}$ corresponds to the null hypothesis that the process has a unit root at the equilibrium, $H_{0}: \sum_{p=1}^{2} \phi_{p}=1$. $Q(4)$ denotes the Ljung-Box $Q$-statistic for serial correlation up to four quarters and $\mathrm{ARCH}(4)$ is the $\mathrm{LM}$ test statistic for conditional heteroskedasticity up to four quarters. 
Table 6: The Consumption-Real Exchange Rate Relationship (Log-Utility Restriction for the US)

\begin{tabular}{|c|c|c|c|c|c|c|}
\hline Country $(j)$ & Japan & Netherlands & Norway & Sweden & Switzerland & U.K. \\
\hline \multirow[t]{2}{*}{ Period } & 1957Q1/ & 1977Q1/ & 1961Q1/ & 1963Q1/ & 1970Q1/ & 1957Q1/ \\
\hline & 2010Q4 & 1998Q4 & 2010Q4 & 2010Q4 & 2010Q4 & 2010Q4 \\
\hline \multicolumn{7}{|c|}{ Mean Equation } \\
\hline \multirow{2}{*}{$\eta_{j}$} & 0.387 & -0.153 & 0.185 & 0.314 & 0.967 & 0.286 \\
\hline & {$[0.000]$} & [0.679] & [0.006] & [0.017] & {$[0.000]$} & {$[0.023]$} \\
\hline \multirow[t]{2}{*}{$\gamma$} & 0.415 & 2.895 & 0.588 & 0.368 & 0.173 & 0.277 \\
\hline & [0.009] & {$[0.000]$} & {$[0.000]$} & {$[0.001]$} & {$[0.000]$} & {$[0.000]$} \\
\hline $\bar{d}$ & 8 & 8 & $3(\mathrm{C})$ & 8 & $8(\mathrm{C})$ & $8(\mathrm{C})$ \\
\hline \multirow{2}{*}{$\ln \left(\frac{\beta_{j}}{\beta_{\mathrm{US}}}\right)$} & 0.004 & -0.008 & -0.005 & & & \\
\hline & [0.040] & {$[0.000]$} & {$[0.000]$} & & & \\
\hline \multicolumn{7}{|c|}{ Variance Equation } \\
\hline \multirow[t]{2}{*}{$\omega$} & $2.19 \times 10^{-3}$ & & $1.69 \times 10^{-3}$ & $1.54 \times 10^{-3}$ & & $1.60 \times 10^{-3}$ \\
\hline & {$[0.000]$} & & {$[0.000]$} & [0.000] & & [0.000] \\
\hline \multirow[t]{2}{*}{$\alpha$} & 0.136 & & 0.075 & 0.385 & & 0.272 \\
\hline & [0.096] & & {$[0.415]$} & [0.001] & & {$[0.000]$} \\
\hline \multicolumn{7}{|l|}{$\xi$} \\
\hline$w^{\mathrm{BW}}$ & $\begin{array}{c}-2.02 \times 10^{-3} \\
{[0.000]}\end{array}$ & & $\begin{array}{c}-1.57 \times 10^{-3} \\
{[0.000]}\end{array}$ & $\begin{array}{c}-1.46 \times 10^{-3} \\
{[0.000]}\end{array}$ & & $\begin{array}{c}-1.36 \times 10^{-3} \\
{[0.000]}\end{array}$ \\
\hline \multirow[t]{2}{*}{$F_{\mathrm{RA}}$} & 33.932 & 9.823 & 146.364 & 27.186 & 0.068 & 8.937 \\
\hline & {$[0.000]$} & [0.003] & {$[0.000]$} & {$[0.000]$} & [0.795] & [0.003] \\
\hline \multirow[t]{2}{*}{$F_{\mathrm{UR}}$} & 0.742 & 2.048 & 9.080 & 1.011 & 0.172 & 0.876 \\
\hline & {$[0.390]$} & [0.157] & [0.003] & [0.316] & [0.679] & [0.351] \\
\hline \multirow[t]{2}{*}{$Q(4)$} & 3.748 & 0.260 & 1.725 & 1.243 & 1.422 & 2.731 \\
\hline & [0.441] & [0.992] & [0.786] & [0.871] & [0.840] & [0.604] \\
\hline \multirow[t]{2}{*}{$\mathrm{ARCH}(4)$} & 0.367 & 0.877 & 0.201 & 0.174 & 1.295 & 0.726 \\
\hline & [0.832] & [0.482] & [0.938] & [0.952] & [0.275] & [0.575] \\
\hline
\end{tabular}

Notes: The table reports estimates of the econometric models in Equations (4) and (6). Figures in square brackets denote $p$-values. (C) indicates the ESTAR parameterization that allows the effect of past deviations from the equilibrium on the speed of mean reversion to be cumulative. The Wald statistic $F_{\mathrm{RA}}$ corresponds to the null hypothesis $H_{0}: \eta_{j}=1 . F_{\mathrm{UR}}$ corresponds to the null hypothesis that the process has a unit root at the equilibrium, $H_{0}: \sum_{p=1}^{2} \phi_{p}=1 . Q(4)$ denotes the Ljung-Box $Q$-statistic for serial correlation up to four quarters and $\mathrm{ARCH}(4)$ is the $\mathrm{LM}$ test statistic for conditional heteroskedasticity up to four quarters. 